\title{
Credit Card Ownership and Usage Behaviour in Botswana
}

\author{
Godfrey Themba (Corresponding author) \\ Department of Marketing, University of Botswana, Private bag 0022, Gaborone, Botswana \\ Tel: 267-35-52980Ｅ-mail: thembag@mopipi.ub.bw \\ Clara. B. Tumedi \\ Department of Marketing, University of Botswana, Private bag 0022, Gaborone, Botswana \\ E-mail: dladyclara@yahoo.com
}

Received: August 19, 2012

Accepted: September 25, 2012

Online Published: October 26, 2012

doi:10.5430/ijba.v3n6p60

URL: http://dx.doi.org/10.5430/ijba.v3n6p60

\begin{abstract}
The study examines credit card ownership and usage in Botswana, and their posited association with consumer demographics and attitude toward debt. In this study, we find that credit card ownership and usage in Botswana are relatively high and that these appear to be influenced by consumer demographics and in particular income, age, education, gender and marital status as well as attitude towards debt. Attitude towards debt is generally negative across all groups. However, chi-square results suggest that these findings are not statistically significant. Only age and gender seem to be significantly related to attitude towards debt where the youth and females are more likely than other demographic groups to have negative attitude towards debt. The study recommends segmenting the credit card market in Botswana based on consumer demographics and attitudes towards debt.
\end{abstract}

Keywords: Credit card usage, Credit card ownership, Attitude toward debt

\section{Introduction}

Globally, credit card ownership and usage have increased substantially in recent decades (Wickramasinghe \& Gurugamage, 2009). This trend reflects the growing popularity of the credit card as a preferred mode of payment for goods and services in lieu of cash, checks and other forms of payment (Abdul-Muhmin and Umar, 2007). The credit card offers consumers the benefit of acquiring and using goods and services without paying for them with cash, thus removing the burden of carrying cash (Foscht et al. 2010). The credit card also offers consumers access to credit without having to go through elaborate paper work as is the case with a loan. Despite these benefits, credit card ownership and usage have been associated with increased consumer debt and unplanned spending (Thomas et al. 2010; Norum 2008). Research shows that debt associated with credit card usage has been on the rise in recent decades and that credit card related debt account for a substantial share of household spending (Wickramasinghe \& Gurugamage, 2009). This has raised concern amongst policy-makers regarding the potential adverse effects on consumers and the economy at large (Norum, 2008).

Extensive research has been conducted on credit card ownership and usage behaviour in recent years (e.g. Kaynak et al. 1995; Sharpe et al., 2012). This research reflects similarities and differences in credit card ownership and usage among nations (Kaynak et al. 1995). The research also indicates that credit card ownership and usage are largely influenced by demographic characteristics of users such as gender, age, education level, income, marital status, ethnic background, culture and attitude towards debt (Abdul-Muhmin and Umar, 2007; Wickramasinghe \& Gurugamage, 2009). Furthermore research indicates that credit card ownership influences usage behaviour and vice versa (Abdul-Muhmin and Umar, 2007; Wickramasinghe \& Gurugamage, 2009). For example, studies have found that the number of credit cards owned increases the frequency of use or amount of purchases charged to the credit card (e.g. Gan et al. 2008; Abdul-Muhmin and Umar, 2007). Similarly, the number of credit card owed is influenced by how the card is used. For example, research has shown that those who use the credit card as a convenient way to pay for goods and services are more likely to own fewer cards than those use it as a source of revolving credit (Wickramasinghe \& Gurugamage, 2009, Kaynak et al. 1995). 
However, the accumulated knowledge on credit card ownership and usage is largely based on studies undertaken in middle and high income countries such as Malaysia, Singapore, Saudi Arabia, China and USA. Low income countries particularly in Africa have attracted little research attention. Despite the recent upgrading of Botswana to middle income status, only one study by Pebe et al. (2012) has been conducted in this area in the country to date. Moreover, this study investigates the usage patterns of credit card owners amongst working Batswana focusing only on six variables influencing credit card debt. The study does not include other variables of interest and in particular demographic variables that previous studies have found to be influencing credit card usage. The present study addresses these research gaps by investigating the posited associations between credit card ownership and usage and demographic characteristics of cardholders in the context of Botswana.

This paper is divided as follows: After introduction is literature review and hypotheses generation. This is followed by the methodology, presentation of the main findings and discussions. The paper concludes with implications of the findings and directions for further research.

\section{Literature Review \& Hypotheses}

This review focuses on literature relating to credit card ownership and usage in different national contexts and, among different demographic groups. According to the literature, similarities and differences in credit card ownership and usage exist amongst nations (Wickramasinghe \& Gurugamage, 2009; Kaynak et al. 1995). For example, Kaynak and Ugar (1984) found similarities in attitudes towards credit card among American and Canadian consumers. There is also evidence that credit card ownership and usage vary amongst nations (Abdul-Muhmin and Umar, 2007). In general credit card ownership and usage levels are higher in countries where "per capita income is high and infrastructure for processing electronic payments is highly developed and widely available" (Abdul-Muhmin and Umar, 2007). Kaynak and Harcar (2001) found that there was a close relationship between the spread of credit card usage in a given country and its socio-economic development. Abdul-Muhmin and Umar (2007) noted that in developed countries like America, credit card diffusion can be as high as $100 \%$. Norum (2008) estimated that in America between $70 \%$ and $80 \%$ of college students own at least one credit card and that the average student has three. Thomas et al. (2010) noted that on average an American carries 4.4 cards in his/her wallet. By contrast the credit card market in India is reported to be low due to the fact that $40 \%$ of the population do not own a bank account (Khare et al. 2012). Similarly, Pebe et al. (2012) reported minimal credit card usage and ownership in Botswana.

Previous research has also found differences in credit card ownership and usage among countries at the same level of economic development (Metwally, 2003). For example, credit card ownership and usage levels are generally higher in America than in most other developed countries (Abdul-Muhmin and Umar, 2007). Metwally (2003) found that credit card ownership and usage were different in Qatar than in Saudi Arabia. According to Abdul-Muhmin and Umar (2007) these differences arise because of different cultural influences on credit card ownership and usage. Being the home of Islam Saudi Arabia is more conservative than Qatar when it comes to the application of Islamic laws regarding the payment of interest.

Literature also indicates that credit card ownership and usage behaviours differ according to the demographic characteristics of users (e.g. Ramayah et al. 2002). Several studies have indicated that credit card ownership and usage are influenced by age, education, income, gender, marital status, ethnicity and attitude towards debt amongst others (Ramayah et al. 2002; Kaynak and Harcar, 2001; Wickramasinghe \& Gurugamage, 2009; Abdul-Muhmin and Umar, 2007). Sharpe et al. (2012) found that in Urban China those who owned credit card were likely to be under the age of 35 and more informed about credit card characteristics. Abdul-Muhmin and Umar (2007) found that in Saudi Arabia credit card ownership was positively related to age, education, income and attitude towards debt. Kaynak and Harkar (2001) found that in Turkey credit card usage was influenced by knowledge structures, beliefs and attitudes of owners. In their study of cardholders in Singapore Gan et al. (2008) found that ownership was significantly influenced by income, gender and perceptions about credit card.

According to the extant literature consumers basically use credit card either as a convenient way to pay for goods and services in lieu of cash or as a form of revolving credit (Nasir, 2006; Barker and Sekerkaya, 1992). Convenience users essentially pay their outstanding monthly balances in full and thereby avoid paying interest whilst "revolvers" are liable to pay interest on outstanding monthly balances. Abdul-Muhmin and Umar (2007) found that in Saudi Arabia the tendency to revolve was related to gender, education and number of cards owned. Other studies have found that revolvers tend to be the young, the less educated, low income earners, the unmarried and those with more liberal attitudes towards debt (Abdul-Muhmin and Umar, 2007; Khare et al. 2011). Similarly, studies have shown that convenience users tend to be those of older age, advanced educational level, higher income, married and those 
who hold a more conservative view towards debt (Abdul-Muhmin and Umar, 2007). In contrast Wickramasinghe \& Gurugamage (2009) found that in Sri Lanka over $74 \%$ of the respondents across all demographic strata were revolvers.

Empirical studies have also highlighted gender differences in credit card ownership and usage (Abdul-Muhmin and Umar, 2007; Khare et al. 2011; Kaynak et al. 1995). Khare et al. (2011) found that in India males are more likely than their female counterparts to own a credit card. Several other studies have also indicated that males are likely to own more cards and to use them as a form of revolving credit than females (Khare et al. 2011). In contrast, Abdul-Muhmin and Umar (2007), Hayhoe et al. (1999) and Kaynak et al. (1995) found that females are more likely to own credit cards than their male counterparts. Rob (2011) after investigating the financial knowledge and credit card behaviour of college students, concluded that females are more likely to engage in risky credit card behaviour than males. In contrast Abdul-Muhmin and Umar (2007) found that males are more likely to be revolvers than females. Gender differences in regard to the type of products and services purchased using credit cards have also been reported (Kaynak and Harcar, 2001; Wickramasinghe \& Gurugamage, 2009). According to available empirical evidence women tend to use credit cards to purchase household goods, clothing and personal belongings whilst men use them for to pay for electronics, entertainment, travel and food (Kaynak and Harcar, 2001).

Credit card ownership has also been found to be having an influence on usage behaviour and vice versa (Ramayahet al. 2002; Abdul-Muhmin and Umar, 2007). Ramayah et al. (2002) found that in Malaysia the number of credit card owned significantly influenced usage level. Similarly Abdul-Muhmin and Umar (2007) found that in Saudi Arabia usage intensity increased with the number of credit card owned. They further found that those who owned two cards were more likely to revolve than those who owned fewer cards. Gan et al. (2008) found that in Singapore those who owned more cards were more likely to be revolvers. Ramayah et al. (2002) also found that in Malaysia, usage level was higher amongst cardholders who owned more cards. Other studies have also found that usage behaviour influenced ownership. For example, Gan et al. (2008) found that the respondents who used their credit cards daily or at least once a week owned more cards than those who use their credit card less frequently. Similarly Hirshman (1979) found that those with two types of cards spent more than those with only one card.

To conclude, it is evident from the literature reviewed that there has been much research attention focused on credit card ownership and usage behaviour in middle and high income countries in recent years. Low income countries particularly in Africa have attracted little research attention. Although Botswana is now an upper -middle -income developing economy with a per capita GNP of $\$ 3312$ (UNCTD, 2003), only one study by Pebe et al. (2012) has been conducted in this area in the country to date. Moreover, this study investigates the usage patterns of credit card owners amongst working Batswana focusing only on six variables influencing credit card debt. The study does not include other variables of interest and in particular demographic variables that previous studies have found to be influencing credit card usage. Therefore by investigating the posited associations between credit card ownership and usage and demographic characteristics of cardholders in the context of Botswana, the present study seeks to address the paucity of literature relating to Botswana and to add further insights to the existing body of knowledge in this area, in general.

Based on the literature reviewed and the researcher's prior insights the following hypotheses relating to credit cardholders in Botswana are postulated:

H1.1: Credit card ownership differs according to demographic characteristics of users.

H1.2: Credit card usage differs according to demographic characteristics of users.

H2: $\quad$ Credit card ownership differs according to usage and vice versa.

H3: Attitude towards debt vary according to demographic characteristics of credit cardholders

H4:1 Cardholders who own more than one card are more likely to have a positive attitude towards debt. Similarly, cardholders who own only one card are more likely to have a negative attitude towards debt

H4.2: Cardholders who revolve are more likely to have a positive attitude toward debt. Similarly, non-revolving cardholders are more likely to have a negative attitude toward debt.

\section{Methodology}

A descriptive research design was deemed suitable for the present study because credit card ownership and usage is an extensively researched area and the key variables well documented in the literature. A convenience sample was selected using the mall-intercept technique which has been widely used and recommended in literature (Khare et. al. 2012; Subramaniam and Marimuthu, 2010; Ahmed et al. 2010). This method is considered to be generally free of 
systematic bias and it gives respondents a sense of anonymity (Khare et. al. 2012). The respondents were asked beforehand if they owned a credit card and only those who answered in the affirmative were given the questionnaire to complete in the presence of the researcher. Following previous studies a structured questionnaire was used to collect data (Khurana and Singh, 2011). To enable subjective and objective data to be collected the questionnaire included closed and open ended questions. The questionnaire consisted of two sections. Section A was designed to collect information relating to ownership and usage of credit card in Botswana. Information relating to ownership was gathered using questions that required respondents to state the number of credit cards that they owned. Information regarding usage was gathered by asking respondents to state how frequently they used credit cards in a month and whether they paid their monthly credit card balances in full (convenience users) or in part (revolving users). Additional information regarding attitude towards debt was also gathered by asking respondents whether in their view using credit card is a good or bad thing. Section B was designed to generate information relating to demographic characteristics of the respondents including age, gender, occupation, educational qualification and income range as well as attitudes towards debt. In total 130 usable questionnaires were collected.

\section{Findings}

\subsection{Demographic Profile of the Respondents}

Of the 130 usable responses 63 (48.5\%) were male and 67 (51.5\%) were female. There were two age categories, the youth aged between 16 and 35 and adults aged 36 and above. The youth category constituted the majority with 79 $(60.8 \%)$ respondents whilst the adult made up the remaining 51 (39.2\%). Among the respondents $73(56.2 \%)$ were singles whilst 57 (43.8\%) were married. Furthermore, 68(53\%) of the respondents had a high educational level (at least a university degree) whilst $61(47 \%)$ had a low educational level. The majority (69\%) of the respondents fall in the income category of high whilst $40(31 \%)$ are in low income category. With regard to attitude towards debt 98 (75.4\%) respondents have a negative attitude whilst $32(24.6 \%)$ had a positive attitude. The demographic profile of the respondents is reflected in Table 1.

$<$ Insert Table1 Here $>$

\subsection{Credit Card Ownership}

In the present study about $78 \%$ of the respondents reported owning one credit card whilst $22 \%$ owned at least two cards (Table 2). Based on these findings it is clear that the majority of the respondents own one card. This finding was also reflected in a similar study conducted in Botswana by Pebe et al. (2012) where $41.5 \%$ of the respondents reported owning just one card whilst $6.5 \%$ and $1 \%$ owned two and three cards respectively. These findings are not very different from findings of studies carried out in other developing middle-income countries. For example, in a study conducted in Turkey Nasir (2006) found that a large proportion of the respondents (31.9\%) owned only two cards. Similarly, in Singapore Gan et al. (2008) found that $65 \%$ of the respondents owned one to two cards whilst in Saudi Arabia Abdul-Muhmin and Umar (2007) reported that the majority owned a maximum of two cards. This level of credit card ownership in developing countries contrasts sharply with that of developed countries like the USA where the average number of cards owned exceeds 4 (Robb, 2011). The results of credit card ownership in this study are reflected in Table 3.

$<$ Insert Table 2 Here $>$

\subsection{Association between Card Ownership and Demographic Characteristics of Cardholders}

We have postulated in this study that credit card ownership in Botswana varies according to demographic characteristics of cardholders. To test this hypothesis, we carried out a cross tabulation of demographic variables by number of cards owned followed by chi-square analysis. The objective was to determine the effect of each variable on credit card ownership. A similar analysis was carried out by Abdul-Muhmin and Umar (2007) to determine the effect of demographic variables on credit card ownership in Saudi Arabia. Our results show that those who own one card are more likely to be those of low income, low education, the youth, male and married people. Similarly those most likely to own more than one card are in the categories of high income, high education, adult, female and single. These are both intuitive and consistent with previous studies (Khare et al. 2012; Gan et al. 2008, 2006; Abdul-Muhmin and Umar, 2007). For example Gan et al. (2008) found that the number of credit cards held was influenced by annual income and gender. They concluded that a higher level of annual income is associated with a greater number of credit cards. They also found that female credit cardholders tend to hold a higher average number of credit cards than males. Abdul-Muhmin and Umar (2007) found that the incidence of credit card ownership increased with age, income and education. However, in contrast to the above studies, our chi-square results indicate 
that none of the observed differences are statistically significant. Thus H1.1 is not supported. The results are shown in Table 3 below.

$<$ Insert Table 3 Here $>$

\subsection{Credit Card Usage}

Credit card usage was examined in this study based on how frequently the card is used in a month and how the outstanding balance on the credit card is paid -whether in full (non-revolving) or in part (revolving). As reflected in table 4 , a total of $52(40 \%)$ respondents used their cards less frequently while $78(60 \%)$ used them more frequently. Furthermore, those who revolve are in the majority (72\%) compared to non-revolvers (28\%). This result contrasts with the findings in Saudi Arabia where Abdul-Muhmin and Umar (2007) found that the overwhelming majority $(68.3 \%)$ of the respondents paid their monthly balances in full whilst $31.7 \%$ made partial payment therefore reflecting a general orientation towards non-revolving. These differences have been attributed to the fact that in Islamic states, the payment of interest is forbidden therefore credit card owners pay off their balances in full to avoid paying interests (Abdul-Muhmin and Umar, 2007). For example, in a study conducted by Wickramasinghe \& Gurugamage (2009) on credit card ownership and usage practices in Sri Lanka, which like Botswana is a non-Islamic state, over $80 \%$ of the total respondents did not pay their monthly balances in full, which highlighted their usage status as revolvers.

$<$ Insert Table 4 Here $>$

\subsection{Association between Credit Card Usage and Demographic Characteristics of Users}

It has been shown in past studies that demographic characteristics of cardholders influence usage of credit card (Abdul-Muhmin and Umar 2007; Gan et al. 2008; Khare et al. 2012; Ramayah et al. 2002). For example Ramayah et al. (2002) found that credit card usage level was dependent on age with older people more likely to have a higher usage level than the young. Based on available evidence and the researchers' insights it was postulated in this study that credit card usage in Botswana differs according to demographic characteristics of cardholders. To test the hypothesis, cross tabulation of demographic characteristics of cardholders by credit card usage was carried out, followed by chi-square analysis. Abdul-Muhmin and Umar (2007) and Ramayah et al. (2002) also carried out similar analyses to determine the effect of demographic variables on credit card usage in Saudi Arabia and Malaysia respectively. Based on cross tabulation (Table 5) results it appears that revolvers are more likely to be those in the group categories of high income, low education, adult, male, and married. Similarly, those most likely to use credit card more frequently are in the group categories of low income, high education, adult, male and married.

The result regarding the association of income, education and age with usage (measured in terms of tendency to revolve) does not appear to be intuitive and consistent with previous studies. In line with common sense and available empirical evidence we expected those in the high income group (and by extension those who are highly educated) to pay their balances in full (non-revolving) since they can afford to do so. Similarly, we expected those who are less educated (and by extension the low income earners) and the young people to pay their outstanding balances in part (revolving) since previous studies have shown that this group generally use credit card as a source of revolving credit. A possible explanation for this result is that in Botswana the credit ceiling for high income earners is very high and in most cases even higher than the monthly income. Wickramasinghe \& Gurugamage (2009) have shown that credit card usage is related to the credit ceiling. The result relating gender to tendency to revolve seems to be consistent with previous studies. In their study Abdul-Muhmin and Umar (2007) also found that revolving behaviour was significantly higher among males. However, the result relating marital status to tendency to revolve seems to be inconsistent with previous studies which indicate that married people tend to be more wary of interest payment than singles (Gan et al. 2008).

The results relating usage (in terms of frequency) to income, age, gender and marital status also seem to be inconsistent with previous studies. In line with previous studies, we expected the frequency of use to increase with the level of income and age (Abdul-Muhmin and Umar 2007). Similarly based on available evidence we expected females and singles to use credit card more frequently. The result with regard to education seems to be in line with previous studies which show that those with higher level of education tend to use credit card more frequently (e.g. Abdul-Muhmin and Umar 2007).

However, chi-square results (Table 5) indicate that there are no statistically significant differences in credit card usage among the different demographic groups. Thus H1.2 is not supported.

$<$ Insert Table 5 Here $>$ 


\subsection{Association between Credit Card Ownership and Usage}

It has also been found in previous studies that credit card usage is related to ownership (Gan et al. 2008). Therefore, we postulated in this study that credit card usage vary according ownership. To test the hypotheses we cross tabulated usage by ownership and then carried out chi-square analyses. Based on the results of cross tabulation of usage (measured as tendency to revolve) by ownership (Table 6) those who own one card are more likely to be non-revolvers. Similarly, the results show that those who own more than one card are more likely to be revolvers. These findings are supported by previous studies (e.g. Abdul-Muhmin and Umar, 2007). Hirschman (1979) had similar findings whilst Gan et al. (2008) argue that credit revolvers tend to hold more cards so as to roll over their credit card debts. However, chi-square results indicate that this finding is not statistically significant at .05 level $(\mathrm{p}=.647)$.

The results of cross tabulation of usage (frequency of use) by ownership indicate that those who own one card are more likely to use credit card frequently and that those who own more than one card are more likely to use the cards less frequently. These findings are both counter intuitive and inconsistent with previous studies. Ordinarily one expects those who own more cards to use credit card more frequently. In their study Ramayah et al. (2002), found that credit card usage increased significantly with the number of credit card held. Gan et al. (2008) in a study of credit card ownership, usage patterns and perceptions in Singapore found that the respondents who use their credit cards daily or at least once a week tend to hold more cards compared to those who use their credit cards less frequently. However, based on the chi-square results our findings are statistically significant at .05 level ( $\mathrm{p}=0.023)$. Thus based on the findings outlined above $\mathrm{H} 2$ is partially supported.

$<$ Insert Table 6 Here>

\subsection{Attitudes towards Debt}

Of the 130 respondents, 98 (75.4\%) expressed negative attitude towards debt whilst 32 (24.6\%) had a positive attitude. Clearly the majority of the respondents have a negative attitude towards debt. For a country which has one of the lowest debt ratios in the developing world, it is not surprising that most people have a negative attitude towards debt. Despite this anecdotal evidence suggest that the level of personal debt in Botswana is increasing.

\subsubsection{Association between Attitude towards Debt and Demographic Characteristics of Cardholders}

Previous research has shown that attitude toward debt is related to demographic characteristics of cardholders (Ramayah et al. 2002). Therefore in this study we postulated that attitude towards debt varies according to demographic characteristics of credit cardholders. The results of cross tabulation (Table 7) show that those with positive attitude towards debt are more likely to be in the group categories of low income, high education, adult, male and married. Similarly, those with negative attitude towards debt are in the group categories of high income, low education, youth, female and single. These results contradict previous studies, which indicate that negative attitude towards debt is associated with low income, education, old age, male and married. However, chi-square analysis indicate that only the results relating to age $(\mathrm{p}=.002)$ and gender $(\mathrm{p}=.001)$ show significance. Thus $\mathrm{H} 3$ is partially supported. These results are reflected in Table 7.

$<$ Insert Table 7 Here $>$

\subsubsection{Association between Attitude towards Debt and Credit Card Ownership}

Previous studies have also indicated that attitude toward debt influences credit card ownership (Abdul-Muhmin and Umar, 2007). Thus in this study attitude toward debt is posited to be positively related to credit card ownership. The results of cross tabulation (Table 8) show that those who own one card are more likely to have negative attitude towards debt. This result makes intuitive sense and is consistent with previous studies (e.g. Ramayah et al. 2002). However, the result also shows that those who own more than one card are also more likely to have negative attitude towards debt. This result seems counter-intuitive and contradictory to previous studies. A possible explanation of this result is that people may use credit card not because they like doing so but because circumstances force them to dos so.

\subsubsection{Association between Attitude towards Debt and Credit Card Usage}

In line with previous studies, we postulated in this study that revolving cardholders are more likely to have a positive attitude toward debt. Similarly we postulated that non-revolving cardholders are more likely to have negative attitude towards debt. However, the results of cross tabulation indicate that both revolvers and non-revolvers are more likely to have negative attitude towards debt. These findings suggests are at odds with previous studies which show that 
revolvers are more likely to have positive attitudes towards debt and that non-revolvers have negative attitudes towards debt (Abdul-Muhmin and Umar, 2007.

However, chi-square results (Table 8 ) indicate that attitude towards debt is not significantly related to both credit card ownership and usage. Hence H4.1 and H4.2 are not supported in this study.

$<$ Insert Table 8 Here $>$

\section{Discussions of Findings}

The present study set out to investigate credit card ownership and usage behaviour in Botswana with particular emphasis being on the posited association with demographic characteristics of cardholders and their attitudes towards debt.

\subsection{Ownership}

The results of the present study show that the majority of the respondents (78\%) own one card and that only $22 \%$ own at least two cards. This result parallel that of Pebe et al. (2012) where $41.5 \%$ and $6.5 \%$ of respondents were reported to own 1 and 2 cards respectively. These results are also in tandem with most studies undertaken in other developing countries where credit card ownership generally ranges between one and two in the majority of cases (e.g. Gan et al. 2008; Ramayah et al. 2002).

\subsection{Association between Ownership and Demographic Profile of Cardholders}

The findings of the present study indicate that credit card ownership in Botswana appear to differ according to demographic characteristics of cardholders. Specifically the findings indicate that those in the group categories of low income, low education, youth, male, and married are more likely to own one card. Similarly, our study suggests that those in the group categories of high income, high education, adult, female and single are more likely to own more than one card. With few exceptions these findings find support in studies conducted elsewhere (e.g. Gan et al. 2008; Abdul-Muhmin and Umar, 2007). In the present study however, this finding is not statistically significant.

\subsection{Usage}

The results show that $60 \%$ of credit cardholders use their cards frequently and that $72 \%$ use credit card as a source of revolving credit. These results suggest that there is a relatively high level of credit card usage in Botswana as compared to some of the developing middle income countries. For example, Gan et al. (2008) reported that in Singapore $54 \%$ used credit card less frequently, reflecting low usage rate. The result however, seems to contradict the findings from another study in Botswana where $48.5 \%$ of the respondents used credit card at least once a month (Pebe et al. (2012). As for the tendency to revolve, these findings are supported by studies conducted in other non-Islamic countries where revolving has been shown to be relatively high (e.g. Wickramasinghe \& Gurugamage, 2009). The results from studies conducted in Islamic countries such as Saudi Arabia (e.g. Abdul-Muhmin and Umar, 2007) and Singapore (e.g. Gan et al. 2008) indicate that the majority pay their monthly credit card bill in full. This tendency to pay the monthly credit card bill in full has been attributed to the Islamic prohibition of paying interest (Abdul-Muhmin and Umar, 2007).

\subsection{Association between Usage and Demographic Profile of Cardholders}

The results indicate that there is an association between usage and demographic characteristics of users. Specifically the findings suggest that those in the group categories of low income, low education, youth, male and married are more likely to be revolvers and to use credit card more frequently (perhaps buying groceries or other small purchases) than other groups. With few exceptions these findings are both intuitive and consistent with some of the studies conducted in other countries (e.g. Khare et al., 2011; Wickramasinghe \& Gurugamage, 2009). The low income earners (and by extension those with low education) would be tempted to use available credit but then find it difficult to pay outstanding monthly balances due to low income. Moreover, due to the low credit ceiling of low income people they tend to use credit card to purchase groceries or small purchases which are made frequently. Young males have also been found to be frequent users in India (Khare et al., 2011). However, Kaynak et al. (1995) found that in Turkey females, highly educated people and high income groups used credit cards more often than do their counterparts.

\subsection{Association between Credit Card Ownership and Usage}

Our findings suggest that there is an association between credit card ownership and usage. Specifically the results suggest that those who own one card are more likely to pay their balances in full and are more likely to use credit card more frequently. Similarly, the results show that those who own more than one card are less likely to pay their 
credit card balances in full (revolvers) and are more likely to use credit card less frequently. The results regarding the association between ownership and usage (measured by payment of outstanding balance) are both intuitive and consistent with previous studies (Ramayah et al. 2002). However, the results regarding the association between ownership and usage (measured by frequency of use) seem to be both counter-intuitive and inconsistent with previous studies. We expected higher usage among those who own more cards than one. Perhaps this unexpected result could be explained by the fact that the respondents may have been confused when asked to state how frequently they used their credit card in a month. For example, to some respondents using credit card twice a month may be deemed to be frequent whilst to others it may not. By contrast, the respondents would not have experienced any difficulty regarding whether or not they paid their monthly outstanding balance in full.

\subsection{Attitude towards Debt}

The results of the present study indicate that an overwhelming majority (75.4\%) of the respondents have negative attitudes towards debt. Furthermore the result from chi-square analysis shows that there is a significant association between attitude towards debt and age $(\mathrm{p}=.002)$ and gender $(\mathrm{p}=001)$. In other words, adults and males are more likely to have positive attitude towards debt. Similarly, the result shows that the youth and females are more likely to have negative attitude towards debt. These results appear to make sense in the context of Botswana where the youth and females experience the highest level of unemployment compared to adult males. Consequently the youth and female are more exposed to the adverse effects of debt than adult males. This is likely to cause make them develop negative attitude debt.

\subsection{Association between Attitude toward Debt and Demographic Profile of Cardholders}

The results indicate that the respondents are more likely to have negative attitude toward debt regardless of their demographic profile. This is in contrast to other studies which indicate that those who have positive attitude towards debt are more likely to own more cards than those who have negative attitude (e.g. Ramayah et al. 2002). Similarly, studies have shown that those who have positive attitude towards debt are more likely to revolve than those who have negative attitude towards debt. Our finding could be explained by the fact that people may be forced to use credit card against their will by circumstances beyond their control. For instances, aggressive marketing of credit cards by financial institutions and the effects of general economic downturn could culminate in people using credit cards even if they don't like it.

\subsection{Association between Attitude toward Debt and Credit Card Ownership}

Our results indicate that in Botswana credit cardholders are likely to have a negative attitude towards debt regardless of the number of cards owned. This result seems to be both counter intuitive and inconsistent with previous studies. However, this result could also reflect an important aspect of credit card ownership which previous studies may have overlooked: people may own and use credit cards not because they like doing so but because circumstances forces them to that. The circumstances may range from lack of financial resources to aggressive marketing of credit cards. In fact it has been shown that one of the main reasons there has been increased usage of credit cards both in developing and developed nations is the way these products have been marketed which makes it easy to obtain a credit card.

\subsection{Association between Attitude toward Debt and Credit Card Usage}

The results also indicate that in Botswana both non-revolvers and revolvers have negative attitudes toward credit card. This finding makes sense given that an overwhelming majority of the respondents have negative attitude towards debt. However, the results is inconsistent with previous studies which show that those with negative attitude towards debt are more likely to pay off their credit card balances in full whilst those with positive attitudes are more likely to make partial payment.

\section{Managerial Implications}

From a managerial perspective, the findings of this study provide useful insights into the credit card market in Botswana. Specifically, the findings indicate that for purposes of marketing their credit cards financial institutions must consider differentiation based on demographic characteristics of users. The results also indicate that in Botswana the majority of people tend to have negative attitudes toward debt with the youth and females being more likely than other groups to have negative attitude towards debt. This implies that more marketing effort is needed to market credit cards in Botswana and that targeting the youth and females would be particularly difficult. 


\section{Conclusions}

Our study addresses the paucity of literature on credit card ownership and usage behaviour in Botswana. The study indicates that there is a relatively high level of credit card ownership and usage in Botswana. The study also provides further support for the posited association between credit card ownership and usage and demographic characteristics of cardholders as well as attitude towards debt. The study also indicates similarities and differences in credit card ownership and usage between Botswana and other developing countries. For example, in line with previous studies the present study indicates that credit card ownership is related to age, income and education. Similarly the study finds that revolving behaviour in Botswana is more likely among the youth, the low income and those with low education. Unlike in Islamic states revolving behaviour is relatively high in Botswana. The study also provides support for the posited association between credit card ownership and usage and that those who own more cards are more likely not to pay their outstanding balances in full (revolvers). Finally the present study indicates that attitude towards debt is significantly related to age and gender.

\section{Limitations and Directions for Future Research}

Although the study provides useful insights into credit card ownership and usage in Botswana, it has some limitations. First, the study is limited to consumers in Gaborone, the Capital City of Botswana, thereby excludes credit cardholders in rural areas who may show different ownership and usage patterns in line with their demographic profile which is different from that of city inhabitants. Second, the sample size is relatively small in comparison to most studies in this area. Third, the study is limited to the investigation of the posited associations between variables of interest using chi-square analysis. This method is limited in terms of its ability to provide insights into the strength of association as well as cause and effect relationship between variables.

The above limitations provide opportunity for future research. In particular, there is need for a nationwide study of credit card ownership and usage behaviour in Botswana. Such a study could also illuminate further on credit card ownership and usage patterns amongst rural and urban consumers. There is also need for further investigation into the nature and strength of association between credit card ownership and usage and demographic variables of interest.

\section{References}

Abdul-Muhmin, Alhassan G., \& Umar, Yakubu A. (2007). Credit card ownership and usage behaviour in Saudi Arabia: The impact of demographics and attitudes towards debt. Journal of Financial Services Marketing, 12(3), 219-235. http://dx.doi.org/10.1057/palgrave.fsm.4760074

Ahmed, Z. U., Ismail, I., Sohail, M. S., Tabsh, I., \& Alias, H. (2010). Malaysian consumers' credit card usage behaviour. Asia Pacific Journal of Marketing and Logistics, 22(4), 528-544. http://dx.doi.org/10.1108/13555851011090547

Barker, T., \& Sekerkaya, A. (1992). Globalization of credit Card Usage: The Case of a Developing Economy. International Journal of Bank Marketing, 10(6), 27-31. http://dx.doi.org/10.1108/02652329210017299

Gan, L.L. Maysami, R. R.C., \& Koh, H.C. (2008). Singapore credit cardholders: ownership usage patterns and perceptions. Journal of Services Marketing, 22(4), 267-279. http://dx.doi.org/10.1108/08876040810881678

Hayhoe, C. R., Leach, L., \& Turner, P. R. (1999). Disrciminating the number of credit cards owned by college students' credit and money attitudes. Journal of Economic Psychology, 2, 643-56. http://dx.doi.org/10.1086/208748

Hirshchman, E. C. (1979, June). Differences in consumer purchase behaviour of credit card payment system. Journal of Consumer Research, 6, 58-66. http://dx.doi.org/10.1086/208748

Kaynak, E., \& Harcar, T. (2001). Consumer's attitudes and intentions towards credit card usage in an advanced developing country. Journal of Financial Services Marketing, 6(1), 24. http://dx.doi.org/10.1108/08876049510094496

Kaynak, E., \& Ugur, K. (1984). A cross -Cultural Study of Credit Card Usage Behaviours: Canadian and American credit Card Users Contrasted. International Journal of Bank Marketing, 2(2), 113-133. http://dx.doi.org/10.1108/eb010739

Kaynak, E., Kucukemiroglu, O., \& Ozmen, A. (1995). Correlates of credit card acceptance and usage in an advanced developing Middle Eastern country. Journal of Services Marketing, 9(4), 52-63. http://dx.doi.org/10.1108/08876049510094496 
Khare, A., Khare, A., \& Singh, S. (2011). Factors affecting credit card use in India. Asia Pacific Journal of Marketing and Logistics, 24(2), 236-256. http://dx.doi.org/10.1108/13555851211218048

Marimuth, M., \& Subramaniam, R. (2010). Bank credit card and the selection criteria: An exploratory study. African Journal of Business Management, 4(16), 3463-3472. [Online] Available: http://www.acdemicjournals.org/AJBM (15 $5^{\text {th }}$ August, 2012)

Metwally, M. M. (2003). Attitudes of consumers in developing countries towards using credit cards. Journal of International Marketing and Marketing Research, 28(2), 83-96.

Nasir, S. (2006). Consumer Behaviour of Credit Card Users in an Emerging Market. Paper presented at the $6^{\text {th }}$ Global Conference on Business \& Economics held October 15-16, 2006 at Gutman Conference Center, USA.

Norum, P. S. (2008). The role of time preference and credit card usage in compulsive buying behaviour. International Journal of Consumer Studies, 32, 269-275. http://dx.doi.org/10.1111/j.1470-6431.2008.00678.x

Pebe, M., Eze, U. C., Yeow, J. A., \& Li, K. P. (2012). Credit Card Use Patterns among Working Adult in Batswana. International Journal on Social Science Economics \& Art, 2(2), 81-88.

Ramayah, T., Nasurdin, A. M., \& Choo, L. H. (2002). Cardholder's attitude and Bank Credit Card Usage in Malaysia. Asian Academy of Management Journal, 7(1), 75-102.

Robb, Cliff, A. (2011). Financial Knowledge and Credit Card Behaviour of College Students. Journal of Family and Economic Issues. http://dx.doi.org/10.1007/s10834-011-9259-y

Sharpe, D. L., Yao, R., \& Liao, L. (2012). Correlates of Credit Card Adoption in Urban China. Journal of Family and Economic Issues. http://dx.doi.org/10.1007/s10834-012-9309-0

Thomas, F., Maloles III. C., \& Swoboda, B. (2010). Debit and credit card usage and satisfaction: Who uses which and why-evidence from Austria. International Journal of Bank Marketing, 28(2), 150-165. http://dx.doi.org/10.1108/02652321011018332

UNCTAD. (2003). Investment Policy Review Botswana, Geneva. United Nations Publications. [Online] Available: http://unctad.org/en/docs/iteipcmisc10-en.pdf ( $4^{\text {th }}$ September, 2012)

Wickramsinghe, V., \& Gurugamage, A. (2009). Consumer credit card ownership and usage practices: empirical evidence from Sri Lanka. International Journal of Consumer Studies, 33, 436-447. http://dx.doi.org/10.1111/j.1470-6431.2009.00779.x

Table 1. Demographic profile of the respondents

\begin{tabular}{|c|c|c|c|}
\hline \multicolumn{2}{|c|}{ Demographic variable } & $\mathbf{N}$ & $\%$ \\
\hline \multirow[t]{2}{*}{ Gender: } & Male & 63 & 48.5 \\
\hline & Female & 67 & 51.5 \\
\hline \multirow[t]{2}{*}{ Age: } & Youth (16-35) & 79 & 60.8 \\
\hline & Adult(36+) & 51 & 39.2 \\
\hline \multirow[t]{2}{*}{ Marital Status: } & Married & 57 & 43.8 \\
\hline & Single & 73 & 56.2 \\
\hline \multirow[t]{2}{*}{ Education: } & high & 68 & 53 \\
\hline & low & 61 & 47 \\
\hline \multirow[t]{2}{*}{ Income: } & high & 89 & 69 \\
\hline & low & 40 & 31 \\
\hline \multirow[t]{2}{*}{ Attitude: } & Positive & 32 & 24.6 \\
\hline & Negative & 98 & 75.4 \\
\hline
\end{tabular}

Note: Some of the frequencies may not add up to 130 due to missing data

Table 2. Number of credit card owned

\begin{tabular}{ccc}
\hline Number of credit card owned & $\mathbf{N}$ & $\mathbf{\%}$ \\
\hline One & 102 & 78 \\
Two or more & 28 & 22 \\
Total & $\mathbf{1 3 0}$ & $\mathbf{1 0 0}$ \\
\hline
\end{tabular}


Table 3. Cross tabulation of demographic profile by number of cards owned

\begin{tabular}{|c|c|c|c|c|}
\hline \multirow[t]{2}{*}{ Demographic Variable } & \multicolumn{2}{|c|}{$\begin{array}{l}\text { Number (\%) of respondents who } \\
\text { owned: }\end{array}$} & \multirow[t]{2}{*}{ Chi-squares } & \multirow[t]{2}{*}{ p-values } \\
\hline & One card & More than one cards & & \\
\hline Income: High & $69(77.5 \%)$ & $20(22.5 \%)$ & 0.412 (1 d.f) & 0.521 \\
\hline low & $33(82.5 \%)$ & $7(17.5 \%)$ & & \\
\hline $\begin{array}{l}\text { Education: High } \\
\text { low }\end{array}$ & $\begin{array}{l}52(76.5 \%) \\
49(80.3 \%)\end{array}$ & $\begin{array}{l}16(23.5 \%) \\
12(19.7 \%)\end{array}$ & $0.282(1 \mathrm{~d} . f)$ & 0.596 \\
\hline $\begin{array}{l}\text { Age: Youth(16-35) } \\
\text { Adult(36+) }\end{array}$ & $\begin{array}{l}64(81.0 \%) \\
38(74.5 \%)\end{array}$ & $\begin{array}{l}15(19.0 \%) \\
13(25.5 \%)\end{array}$ & 0.776(1d.f) & 0.379 \\
\hline $\begin{array}{l}\text { Gender: Male } \\
\text { Female }\end{array}$ & $\begin{array}{l}52(82.5 \%) \\
50(74.6 \%)\end{array}$ & $\begin{array}{l}11(17.5 \%) \\
17(25.4 \%)\end{array}$ & $1.203(1 \mathrm{~d} . f)$ & 0.273 \\
\hline $\begin{array}{c}\text { Marital Status: Married } \\
\text { Single }\end{array}$ & $\begin{array}{l}49(86.0 \%) \\
53(72.6 \%)\end{array}$ & $\begin{array}{l}8(14.0 \%) \\
20(27.4 \%)\end{array}$ & 3.382(1d.f) & 0.066 \\
\hline $\begin{aligned} & \text { Att. towards debt: }+ \text { ve } \\
&- \text {-ve }\end{aligned}$ & $\begin{array}{l}26(81.2 \%) \\
76(77.6 \%)\end{array}$ & $\begin{array}{c}6(18.8 \%) \\
22(22.4 \%)\end{array}$ & 0.195 (1d.f) & 0.659 \\
\hline
\end{tabular}

Table 4. Credit card usage

\begin{tabular}{ccc}
\hline Usage & N & $\%$ \\
\hline Use more frequently & 78 & 60 \\
Use less frequently & 52 & 40 \\
Non-Revolver & 37 & 28 \\
Revolver & 93 & 72
\end{tabular}

Table 5. Cross tabulation of demographic profile of users by usage

\begin{tabular}{|c|c|c|c|c|c|}
\hline \multirow{2}{*}{\multicolumn{2}{|c|}{ Demographic Variables }} & \multicolumn{2}{|c|}{ Number (\%) of respondents: } & \multicolumn{2}{|c|}{ Number (\%) of respondents: } \\
\hline & & Non-revolvers & Revolvers & More frequently & $\begin{array}{c}\text { Less } \\
\text { Frequently }\end{array}$ \\
\hline \multirow[t]{2}{*}{ Income: } & High & $10(25.0 \%)$ & $30(75.0 \%)$ & $22(55.0 \%)$ & $18(45.0 \%)$ \\
\hline & Low & $27(30.3 \%)$ & $62(69.7 \%)$ & $62(69.7 \%)$ & $27(30.3 \%)$ \\
\hline \multicolumn{2}{|c|}{ Chi-square } & \multicolumn{2}{|c|}{$0.384(1$ d.f $)$} & \multicolumn{2}{|c|}{$2.612(1 \mathrm{~d} . f)$} \\
\hline \multicolumn{2}{|c|}{ p-values } & \multicolumn{2}{|c|}{0.535} & \multicolumn{2}{|c|}{0.106} \\
\hline \multirow[t]{2}{*}{ Education: } & High & $22(32.4 \%)$ & $46(67.6 \%)$ & $45(66.2 \%)$ & $23(33.8 \%)$ \\
\hline & Low & $15(24.6 \%)$ & $46(75.4 \%)$ & $38(62.3 \%)$ & $23(37.7 \%)$ \\
\hline \multicolumn{2}{|c|}{ Chi-square } & \multicolumn{2}{|c|}{$0.947(1$ d.f $)$} & \multicolumn{2}{|c|}{$0.211(1 \mathrm{~d} . f)$} \\
\hline \multicolumn{2}{|c|}{ p-values } & \multicolumn{2}{|c|}{0.330} & \multicolumn{2}{|c|}{0.646} \\
\hline \multirow{2}{*}{ Age: $\quad$ Y } & $\operatorname{th}(16-35)$ & $27(34.2 \%)$ & $52(65.8 \%)$ & $50(63.3 \%)$ & $29(36.7 \%)$ \\
\hline & $\operatorname{lt}(36+)$ & $10(19.6 \%)$ & $41(80.4 \%)$ & $34(66.7 \%)$ & $17(33.3 \%)$ \\
\hline \multicolumn{2}{|c|}{ Chi-square } & \multicolumn{2}{|c|}{$3.231(1$ d.f $)$} & \multicolumn{2}{|c|}{ 0.154(1d.f) } \\
\hline \multicolumn{2}{|c|}{ p-values } & \multicolumn{2}{|c|}{0.72} & \multicolumn{2}{|c|}{0.694} \\
\hline \multirow[t]{2}{*}{ Gender: } & Male & $15(23.8 \%)$ & $48(76.2 \%)$ & $41(65.1 \%)$ & $22(34.9 \%)$ \\
\hline & Female & $22(32.8 \%)$ & $45(67.2 \%)$ & $43(64.2 \%)$ & $24(35.8 \%)$ \\
\hline \multicolumn{2}{|c|}{ Chi-square } & \multicolumn{2}{|c|}{$1.299(1$ d.f $)$} & \multicolumn{2}{|c|}{0.012 (1d.f) } \\
\hline \multirow{3}{*}{\multicolumn{2}{|c|}{\begin{tabular}{c}
\multicolumn{1}{c}{ p-values } \\
Marital Status: Married \\
Single
\end{tabular}}} & \multicolumn{2}{|c|}{0.254} & \multicolumn{2}{|c|}{0.915} \\
\hline & & $13(22.8 \%)$ & $44(77.2 \%)$ & $39(68.4 \%)$ & $18(31.6 \%)$ \\
\hline & & $24(32.9 \%)$ & $49(67.1 \%)$ & $45(61.6 \%)$ & $28(38.4 \%)$ \\
\hline \multicolumn{2}{|c|}{ Chi-square } & \multicolumn{2}{|c|}{ 1.594(1d.f) } & \multicolumn{2}{|c|}{0.643 (1d.f) } \\
\hline \multicolumn{2}{|c|}{ p-values } & & & 0.4 & \\
\hline
\end{tabular}


Table 6. Cross tabulation of credit card usage by ownership

\begin{tabular}{|c|c|c|c|c|}
\hline \multirow[b]{2}{*}{ Credit Card Usage } & \multicolumn{2}{|c|}{ Number (\%) of respondents who own: } & \multirow[b]{2}{*}{ Chi-squares } & \multirow[b]{2}{*}{ p-values } \\
\hline & One card & More than one card & & \\
\hline Non- Revolvers & $30(81.1 \%)$ & $7(18.9 \%)$ & 0.210 (1d.f) & 0.647 \\
\hline Revolvers & $72(77.4 \%)$ & $21(22.6 \%)$ & & \\
\hline Use more frequently & $71(84.5 \%)$ & $13(15.5 \%)$ & 5.163(1d.f) & $0.023 *$ \\
\hline Use less frequently & $31(67.4 \%)$ & $15(32.6 \%)$ & & \\
\hline
\end{tabular}

*Significant at .05 level.

Table 7. Cross tabulation of demographic profiles of users by attitude towards debt

\begin{tabular}{|c|c|c|c|c|c|}
\hline \multicolumn{2}{|c|}{ Demographic Variable } & \multicolumn{2}{|c|}{$\begin{array}{l}\text { Number(\%) of respondents whose } \\
\text { attitude towards debt is: }\end{array}$} & \multirow[b]{2}{*}{ Chi-square } & \multirow[b]{2}{*}{ p-value } \\
\hline \multirow{3}{*}{\multicolumn{2}{|c|}{$\begin{array}{l}\text { High income } \\
\text { Low income }\end{array}$}} & Positive & Negative & & \\
\hline & & $21(23.6 \%)$ & $68(76.4 \%)$ & $0.556(2 \mathrm{~d} . \mathrm{f})$ & 0.757 \\
\hline & & $11(27.5 \%)$ & $29(72.5 \%)$ & & \\
\hline \multirow[t]{2}{*}{ Education } & 1: High & $20(29.4 \%)$ & $48(70.6 \%)$ & $1.635(1 \mathrm{~d} . f)$ & 0.201 \\
\hline & Low & $12(19.7 \%)$ & $49(80.3 \%)$ & & \\
\hline \multirow[t]{2}{*}{ Age: } & Youth & $12(15.2 \%)$ & $67(84.8 \%)$ & $9.641(1 \mathrm{~d} . f)$ & $0.002 *$ \\
\hline & Adult & $20(39.2 \%)$ & $31(60.8 \%)$ & & \\
\hline \multirow[t]{2}{*}{ Gender: } & Male & $24(31.8 \%)$ & $39(61.9 \%)$ & 11.970 (1d.f) & $0.001 *$ \\
\hline & Female & $8(11.9 \%)$ & $59(88.1 \%)$ & & \\
\hline \multicolumn{2}{|c|}{ Marital status: Married } & & & $1.484(1 \mathrm{~d} . \mathrm{f})$ & 0.223 \\
\hline \multirow{2}{*}{\multicolumn{2}{|c|}{ Single }} & $17(29.8 \%)$ & $40(70.2 \%)$ & & \\
\hline & & $15(20.5 \%)$ & $58(79.5 \%)$ & & \\
\hline
\end{tabular}

\section{*Significant at .01 level.}

Table 8. Cross tabulation of attitude towards debt by number of cards owned and tendency to revolve

\begin{tabular}{ccccc}
\hline & Number & $(\%)$ of respondents who own & \multicolumn{2}{c}{ Tendency to revolve } \\
\cline { 2 - 5 } Attitude toward debt: & One card & More than one cards & Non-Revolvers & Revolvers \\
Positive & $26(25.5 \%)$ & $6(21.4 \%)$ & $7(18.9 \%)$ & $25(26.9 \%)$ \\
Negative & $76(74.5 \%)$ & $22(78.6 \%)$ & $30(81.1 \%)$ & $68(73.1 \%)$ \\
Chi-square & $0.195(1 \mathrm{~d} . \mathrm{f})$ & & $0.904(1 \mathrm{~d} . \mathrm{f})$ & \\
p-values & & 0.659 & \multicolumn{2}{c}{0.342} \\
\hline
\end{tabular}

